\title{
PALANQUE ELETRÔNICO EM ELEIÇÕES LOCAIS: ASPECTOS DO ACESSO DOS MUNICÍPIOS AO HGPE NA TELEVISÃO'
}

\author{
Márcia Jardim
}

RESUMO

Este trabalho apresenta aspectos do acesso ao horário gratuito de propaganda eleitoral (HGPE) na televisão em eleições locais nos municípios do estado de São Paulo. Evidências empíricas comprovam a existência de dois modos distintos de fazer campanhas eleitorais locais em municípios com mesmo perfil (conforme critérios sociais, econômicos, políticos e demográficos): os eleitores do Estado de São Paulo podem ser divididos entre aqueles com acesso ao HGPE na televisão para decidir em quem votar para Prefeito de sua cidade e os que não têm acesso a tal fonte de informação política. Apesar de a capital contar com um "palanque eletrônico" para eleger o seu Prefeito desde a eleição municipal de 1985, municípios da região metropolitana de São Paulo não contam com o mesmo recurso - os eleitores de toda a região do ABCD, mais Guarulhos e Osasco, assistem na televisão à propaganda eleitoral dos candidatos da cidade de São Paulo. Este artigo apresenta resultados do levantamento "Aldeia global paulista", que procurou explicar as razões que levaram à configuração desse cenário e identifica a totalidade dos municípios com "campanha eletrônica" para Prefeito.

PALAVRAS-CHAVE: horário gratuito de propaganda eleitoral; eleições para Prefeito; estado de São Paulo; palanque eletrônico.

\section{INTRODUÇÃO}

Este trabalho apresenta aspectos do acesso ao horário gratuito de propaganda eleitoral (HGPE) na televisão em eleições locais de alguns municípios do estado de São Paulo² . Evidências empíricas comprovam a existência de dois modos distintos de fazer campanhas eleitorais locais em municípios com mesmo perfil, de acordo com

1 Este texto é parte dos resultados da pesquisa original realizada para o programa de Mestrado em Ciência Política do Instituto de Filosofia e Ciências Humanas da Universidade Estadual de Campinas (IFCH-UNICAMP), O mapa da mídia eletrônica em eleições locais no estado de São Paulo, de dezembro de 2002 e foi apresentado no XI Congresso Brasileiro de Sociologia, realizado na UNICAMP em setembro de 2003. A autora agradece a leitura crítica e as sugestões feitas pelos pareceristas anônimos da Revista de Sociologia e Política, que foram, sempre que possível, incorporadas. Os erros e limitações que permanecem são de exclusiva responsabilidade da autora.

2 Apesar de o universo da pesquisa ser o estado de São Paulo, o resultado permite sugerir que a tendência encontrada deve repetir-se nos outros estados, considerando que tanto a legislação eleitoral quanto a regulamentação das telecomunicações é de abrangência nacional. critérios sociais, econômicos, políticos e demográficos. Dessa forma, os eleitores do estado de São Paulo podem ser divididos em eleitores com acesso ao HGPE na televisão para decidir em quem votar para Prefeito de sua cidade e os eleitores que não têm acesso a essa fonte de informação política. Apesar de a capital contar com um "palanque eletrônico" para eleger o seu Prefeito desde a eleição municipal de 1985, municípios da região metropolitana de São Paulo ${ }^{3}$ não contam com esse recurso. Os eleitores de todo o ABCD, Guarulhos e Osasco assistem, na televisão, à propaganda eleitoral dos candidatos da cidade de São Paulo. Este artigo apresenta resultados do levantamento "Aldeia global paulista", que procurou explicar as razões que levaram à configuração de tal cenário e apresenta a totalização dos municípios com "campanha eletrônica" para Prefeito.

3 A região metropolitana de São Paulo, segundo a Fundação SEADE, é composta por 38 municípios mais a capital e responsável por cerca de $59 \%$ do eleitorado do estado (SEADE, 2002; TRE-SP, 2004). É consensual que esses municípios desempenham importante papel no cenário político e econômico, não só do estado, mas também do país.

Rev. Sociol. Polít., Curitiba, 22, p. 45-58, jun. 2004 
Do ponto de vista teórico, o trabalho insere-se no amplo campo de estudos sobre as relações entre a mídia e a política e desenvolveu-se sob a ótica da modernização dos processos políticos-eleitorais caracterizados, principalmente, pela centralidade dos meios de comunicação de massa nas campanhas ${ }^{4}$. As democracias contemporâneas, ao longo do tempo, sofreram transformações com efeitos sobre a forma como se dá a representação política. O período recente é caracterizado pelo declínio da identificação partidária como determinante do voto, a importância das pesquisas de opinião e a centralidade da imagem nos processos político-eleitorais (MANIN, 1995).

A partir das eleições presidenciais de 1989, é possível perceber, também no Brasil, as transformações na forma de representação política apontadas. O papel central que a televisão desempenhou na campanha eleitoral que marcou a redemocratização representou uma surpresa, uma "novidade" que estimulou o debate e o desenvolvimento de estudos sobre o impacto da televisão nos processos eleitorais. Após mais de dez anos de "campanhas modernas" no Brasil para Presidente, governadores, senadores, deputados federais, deputados estaduais e prefeitos das capitais, a pergunta que se apresentava era: como esse "processo de modernização das campanhas" dava-se no nível local, nos municípios do interior do estado de São Paulo? O cenário que se apresentava tinha a marca da diferença: havia municípios com acesso ao HGPE na TV para eleição de Prefeito e municípios que não tinham acesso a esse recurso de campanha eleitoral. Para explicar a configuração deste cenário do acesso aos meios de comunicação eletrônicos em eleições locais também foi preciso realizar um levantamento sobre a legislação eleitoral, no período de 1958 a 2000, e sobre a rede de emissoras de televisão no estado.

Como resultado desse trabalho de pesquisa, explicamos que o acesso ao horário gratuito de propaganda eleitoral na televisão, em eleições locais, dá-se a partir de uma complexa articulação entre aspectos de um contexto legal e de um

\footnotetext{
4 É importante esclarecer que não é intenção deste artigo discutir uma possível oposição entre "campanha tradicional" e "campanha eletrônica" e suas conseqüências para a Democracia, tendo em vista ser este um debate atual e nãoconclusivo nas Ciências Humanas. Trata-se, aqui, principalmente de chamar a atenção para a coexistência das duas formas de campanha e as razões que configuraram este cenário.
}

contexto técnico referente às telecomunicações. Ambos os contextos apresentam questões específicas significativas e problematizá-las consiste no objetivo principal deste artigo.

\section{RELAÇÕES ENTRE MÍDIA E POLÍTICA}

O papel central desempenhado pelos meios de comunicação eletrônicos nos processos políticoeleitorais das democracias contemporâneas é algo consensual na literatura como uma das principais evidências da modernização das campanhas eleitorais na "era midiática" (MATOS, 1994; RUBIM, 1994; 2002; AZEVEDO, 2001). Segundo Rubim (2002), as eleições podem ser consideradas como momentos diferenciados no cotidiano dos eleitores, como um período em que as atenções, de alguma forma, ficam mais voltadas para os debates políticos. Após quarenta e um anos de propaganda eleitoral na televisão, o horário gratuito já faz parte da cultura política brasileira (ALBUQUERQUE, 1995) e sua transmissão determina para o eleitor, de maneira inequívoca, o início do "tempo da política" (VIDAL, 1998).

As campanhas eleitorais, principalmente por meio da ação da mídia, são momentos de grande aumento da circulação de informações políticas que, tornadas públicas, podem ser levadas em consideração pelo eleitor no processo de decisão do seu voto (HOLBROOK, 1996). Com base em uma ampla gama de estudos nacionais (STRAUBHAAR, OLSÉN \& CAVALLARI, 1991;AVELAR, 1992; PORTO, 1996; VIDAL, 1998) e internacionais (SKIDMORE, 1993; WOLTON, 1996) podemos considerar a televisão como uma das principais fontes de informação política na contemporaneidade: "A dominância da televisão enquanto fonte de informação política dentre os meios de massa foi confirmada por um survey com amostra nacional de 2680 entrevistados, realizado em outubro de 1989 pelo IBOPE"5 (STRAUBHAAR, OLSÉN \& CAVALLARI, 1991, p. 50).

Nesse sentido, este trabalho considera a existência da propaganda política na televisão uma importante fonte de informação para o eleitor e um dos principais fatores na definição de uma campanha eleitoral moderna. Com pouco mais de meio século de existência, a televisão é o meio de comunicação de massa por excelência e é nesse cenário da sociedade de massa que ela deve ser analisada. Na verdade, desde o seu início, a tele-

\footnotetext{
5 Todas as traduções são da autora.
} 
visão tem sido cercada de concepções ambíguas, em uma mistura de fascínio e desconfiança, de valorização e desprezo. Para Wolton (1996), a televisão desfruta de inegável sucesso popular, porém lhe falta prestígio. Segundo o autor, a televisão desempenha um papel essencial no espaço público contemporâneo: o de "laço social". Não se trata de negar a centralidade da imagem, mas de recusar uma visão da televisão como sendo "manipuladora de consciência". Wolton mostra que o sucesso da televisão reside em outros fatores que não só a transmissão de imagens, mas principalmente na relação singular que ela estabelece, a partir da programação, com o "grande público": um telespectador ativo que sabe que nela encontrará informação, igualdade e diversão. Por um lado, temos uma variada oferta de imagens; por outro lado, um telespectador ativo e inteligente que articula recursos na seleção e interpretação dessas imagens. Como apontou Wolton, as características desse processo de comunicação encerram inúmeras contradições e apresentam grandes limitações - mas o que importa é resgatar a possibilidade de sua dimensão democrática. Assim, a forma como a televisão relaciona-se com a política, por exemplo, nos processos eleitorais, não está dada a priori; ou seja, ela não é necessariamente negativa nem positiva e essa relação poderá ser mais ou menos democrática, dependendo do contexto político do país naquele momento.

Identificamos os recursos de comunicação política utilizados em campanhas eleitorais para Prefeito com o objetivo de caracterizar uma "tipologia" de campanha. É possível dizer que em uma campanha eleitoral existem dois conjuntos de ações: um que envolve ações de contato direto com o candidato majoritário e outro que utiliza recursos para mediar a relação eleitor-candidato. Para uma melhor caracterização desse universo, definimos duas categorias de campanha política: a tradicional e a eletrônica.

A campanha política "tradicional" utiliza como recursos de comunicação política a distribuição de material gráfico 6 , a realização de comícios ${ }^{7}$,

6 Tradicionalmente, os materiais gráficos utilizados em campanhas políticas no Brasil são: cartazes, modelos de cédulas, jornais, folhetos e "santinhos".

7 Existe uma tendência de "espetacularização" dos comícios políticos. No início, em sua origem, contavam apenas com a presença de lideranças políticas e o candidato majoritário reuniões com a presença do candidato, carreatas e o tradicional corpo-a-corpo dos candidatos com os eleitores; nos municípios com emissoras de rádio, também existe a transmissão de propaganda eleitoral ${ }^{8}$. Já a segunda categoria de campanha, que passaremos a denominar de "eletrônica", faz uso exatamente dos mesmos recursos utilizados na campanha "tradicional", porém com um significativo instrumento adicional: a mídia eletrônica (a televisão).

\section{APERSPECTIVA INSTITUCIONAL-LEGAL}

Em uma tentativa de dimensionar o contexto institucional-legal, é possível identificar dois blocos de questões legais: um ligado à propaganda propriamente dita e um segundo relativo aos meios de comunicação de massa. Como indicativo da importância do primeiro bloco, podemos lembrar que a própria existência do HGPE, principalmente no caso de eleições locais, depende diretamente das leis vigentes e dos seus mecanismos de interpretação e fiscalização ${ }^{9}$.

O segundo bloco de questões institucionallegais trata das implicações, de caráter eminentemente político, das regulamentações das modalidades e concessões de emissoras e retransmissoras de televisão, ou seja, das relações do poder público com os meios de comunicação de massa (GUIMARÃES \& VIEIRA, 1989; LIMA, 1989; 1996; CAIAFA, 1994). A política de concessão de emissoras e retransmissoras de televisão e rádio

era a maior "estrela" do evento. Nas décadas de 1950 e 1960 os comícios dos candidatos a governador eram transmitidos ao vivo pela televisão. Atualmente, os comícios, mesmo nos pequenos centros urbanos, têm-se convertido em verdadeiros espetáculos, com queima de fogos de artifício e presença de artistas famosos.

8 Deve-se notar que, por um lado, a transmissão de propaganda eleitoral gratuita no rádio obedece à mesma legislação eleitoral estabelecida para as emissoras de televisão. Por outro lado, a rede de emissoras de rádio está largamente disseminada pelo estado de São Paulo, sendo muito difícil encontrar uma cidade com mais de três mil habitantes que não disponha de uma estação de rádio local.

9 Outro aspecto importante relativo à legislação eleitoral e que mereceu inúmeros estudos é a análise do efeito das regulamentações sobre o potencial de comunicabilidade da propaganda eleitoral (CUNHA, 1994; RONDELLI \& WEBER, 1994; RUBIM, 1994; ALBUQUERQUE, 1995; JORGE, 1995; LIMA, 1996; MIGUEL, 1997). 
tem sido objeto de exaustivas pesquisas, que demonstram uma grande capacidade dos estudiosos em vencer as dificuldades da falta de sistematização dos dados e elaboração teórica para o desenvolvimento de um novo conceito de coronelismo, o "coronelismo eletrônico" (MOTTER, 1994; COSTA \& BRENER, 1997) ${ }^{10}$.

O modelo brasileiro de propaganda política na televisão (o HGPE) apresenta especificidades que o tornam único, apresentando consideráveis diferenças dos modelos existentes em outros países ${ }^{11}$. O HGPE brasileiro, ao longo dos seus 41 anos de existência, tem oscilado entre os modelos americano e francês. A semelhança com o modelo americano refere-se ao período anterior a 1962, quando a nossa propaganda eleitoral era paga e não sofria praticamente nenhum tipo de regulamentação. Já a semelhança com a França pode ser observada no excessivo número de regulamentações e restrições do período que vai de 1985 a 1992 (ALBUQUERQUE, 1995).

Algumas especificidades do modelo brasileiro chegam a soar até mais como curiosidades do que como mecanismos democráticos de igualdade de acesso aos meios de comunicação (candidatos) e à informação (eleitores). Hoje, o período e o tempo de duração da propaganda eleitoral estão definidos em 45 dias com 130 minutos diários para as eleições gerais; do total, cem minutos estão divididos em dois grandes blocos, um no horário do almoço e outro à noite, no "horário nobre"; os 30 minutos restantes destinam-se aos spots que são distribuídos ao longo da programação diária ${ }^{12}$. O período de propaganda eleitoral gratuita brasileiro é o maior tempo destinado a esse fim entre todos os países que dispõem do recurso (SCHIMITT, CARNEIRO \& KUSCHNIR, 1999).

10 Para uma análise detalhada dos aspectos legais que envolvem a propaganda eleitoral e a concessão de emissoras de televisão no Brasil, cf. Jardim (2002, cap. 2, 3).

11 Sobre os modelos de propaganda eleitoral em democracias ocidentais contemporâneas, cf. Jardim (2002, cap. 2, item 2.3).

12 É atribuição do Tribunal Regional Eleitoral elaborar um Plano de Mídia com antecedência para a distribuição, bastante complexa, entre todas as emissoras e durante toda a programação, dos spots a que tem direito cada partido envolvido na disputa.
Um dos efeitos perversos da tradição do legislativo brasileiro de reformar, constantemente, a legislação é a existência de um HGPE extremamente complexo e todo remendado. O modelo brasileiro, a partir das eleições de 1996, caracteriza-se pela existência de dois formatos de programa: o mais tradicional (de longa duração) e um modelo mais moderno, com inserções curtas (com duração de 30 a 60 segundos) que se assemelham ao padrão dos spots comerciais. A complexidade do modelo brasileiro, além de desvirtuar o objetivo que justificou sua existência primeira (processo de eqüidade de acesso aos meios de comunicação de massa), consegue a incrível proeza de desagradar a todos os atores diretamente envolvidos no drama das campanhas eleitorais. As emissoras de televisão são as primeiras a queixar-se do "abuso" do horário gratuito que só serve para ocasionar prejuízos e "afugentar" a audiência. A classe política nunca chega a um acordo com relação às características do modelo, insistindo, assim, no eterno "estica, encurta, soma, subtrai" dos dias, horários e tempos. A Justiça Eleitoral, por sua vez, reclama da falta de estrutura e recursos para regulamentar e fiscalizar eleições em um país de dimensões continentais ${ }^{13}$.

Analisando a legislação, as resoluções do Tribunal Superior Eleitoral (TSE) e do Tribunal Regional Eleitoral de São Paulo (TRE-SP) e os programas do HGPE de 1958 a 2000, é possível identificar algumas estruturas que se destacam em função dos efeitos que produzem na forma, no conteúdo e na apresentação dos programas de propaganda eleitoral e, conseqüentemente, sobre o seu potencial de comunicabilidade e audiência (JORGE, 1997). Pequenas alterações podem significar grandes diferenças nos efeitos e impactos dos programas de propaganda eleitoral gratuita sobre os eleitores. Evidências dessa afirmação aparecem na ação intervencionista da Justiça Eleitoral a fim de não deixar nenhum detalhe sem uma norma específica de controle (ALBUQUERQUE, 1995). Ao longo do período

13 Em 2002, as eleições gerais foram totalmente informatizadas, ou seja, com urnas eletrônicas. O Brasil é o único país do mundo com domínio dessa tecnologia, desenvolvida a partir de programas (softwares) totalmente nacionais. 
estudado - 1958 a 2000 - o horário gratuito de propaganda eleitoral apresentou-se como sendo mais ou menos informativo e com maior ou menor potencial de comunicabilidade. Mas nesses últimos 41 anos - à exceção do período em que vigorava a Lei Falcão ${ }^{14}$, de 1976 a 1982 - o HGPE sempre desempenhou, se não um papel decisivo como desejavam alguns, pelo menos um papel importante no processo de disputa pelo poder político travado pelos partidos políticos e seus respectivos candidatos. Existe um conjunto de leis elaboradas especificamente para regulamentar os pleitos municipais, apresentando variações significativas com relação às eleições para governadores e Presidente. Mas, para além dessas variações na legislação, existe um ator cuja atuação, por si só, pode definir o acesso de determinado município à propaganda eleitoral na televisão: a Justiça Eleitoral.

\section{A JUSTIÇA ELEITORAL}

A Justiça Eleitoral foi instituída por meio do Código Eleitoral de 1932 com o objetivo de pôr fim às fraudes, vícios e práticas de corrupção até então usuais nas disputas eleitorais (LEAL, 1975). Durante o Estado Novo, os partidos políticos, as eleições e a Justiça Eleitoral foram extintos até a Constituição de 1946, quando ela foi criada novamente (TRE-SP, 2004). A Justiça Eleitoral é a única área da justiça brasileira que não possui quadro próprio de funcionários e juízes. Ela é uma ramificação da Justiça Federal. O Artigo 121 da Constituição Federal de 1988 prevê edição de Lei Complementar dispondo sobre a organização e competência dos tribunais, dos juízes de Direito e das juntas eleitorais, mas, até setembro de 2000 , ela ainda não havia sido elaborada.

Com a finalidade de aperfeiçoar as eleições, várias foram as atribuições que passaram a ser de competência exclusiva da Justiça Eleitoral: alistamento eleitoral, registro e cassação de candidatos, julgamento de crimes eleitorais, fiscalização da propaganda eleitoral, apuração, proclamação e diplomação dos eleitos (ibidem). Para organizar, administrar e controlar os pleitos

\footnotetext{
14 Lei n. 6 339, de 1. jul.1976, que limitou a propaganda eleitoral na televisão e rádio à veiculação exclusiva da foto e currículo dos candidatos, sendo totalmente vetado qualquer outro tipo de propaganda.
}

a cada eleição e de acordo com a necessidade, a Justiça Eleitoral edita resoluções com normas e procedimentos para cada pleito específico.

A divisão eleitoral do país obedece a critérios próprios da Justiça Eleitoral, mas guarda algumas semelhanças com a divisão político-social da Federação. A Justiça Eleitoral é dividida em instâncias autônomas, porém hierarquizadas. Seu órgão máximo é o Tribunal Superior Eleitoral e cada estado possui um Tribunal Regional Eleitoral. Os municípios são divididos em zonas eleitorais e estas em seções com um número máximo aproximado de 400 eleitores cada. Para cada Zona Eleitoral é designado um Juiz Eleitoral de primeira instância.

O funcionamento da Justiça Eleitoral assemelha-se ao da Justiça Comum. O Tribunal Superior Eleitoral, responsável pela coordenação das eleições nacionais, e os tribunais regionais, responsáveis pelas eleições estaduais, possuem estrutura mínima de pessoal e definição clara de critérios para nomeação dos juízes (SADEK, $1995)^{15}$. Essa realidade não se reproduz em eleições municipais, a começar pelo critério de acesso ao cargo de Juiz Eleitoral, que não se dá por intermédio de eleições. Os Juízes Eleitorais de primeira instância são indicados por uma espécie de colegiado entre os Juízes da Comarca que declaram interesse na nomeação, em que um dos principais critérios utilizados nesse processo de nomeação é o de antigüidade, ou seja, os anos trabalhados no Judiciário.

Os procedimentos adotados para nomeação de Juízes Eleitorais de primeira instância evidenciam a ausência de uma política de competência ou mérito no desempenho das funções de Juiz Eleitoral. Também não há regras definidas para o

15 "Nas eleições estaduais atuam os tribunais regionais eleitorais, com a função de coordenar e centralizar o registro de candidatos e a proclamação e diplomação dos eleitos. Esses tribunais são compostos por dois desembargadores e dois juízes da Justiça Estadual, eleitos por um período de dois anos pelos respectivos tribunais de Justiça, dois juristas e um Juiz Federal. Nas eleições nacionais o processo é coordenado pelo Tribunal Superior Eleitoral, formado por três ministros do Supremo Tribunal Federal (STF), dois ministros do Superior Tribunal de Justiça e dois juristas escolhidos pelo Presidente da República, a partir de listas tríplices elaboradas pelo STF" (SADEK, 1999). 
tempo de permanência do Juiz que pode exercer a função por apenas um ou dois pleitos. Na maioria das vezes, o Juiz Eleitoral acumula funções e atribuições de sua outra ocupação junto à Justiça Federal, o que significa acumular responsabilidades e também vencimentos.

O Juiz Eleitoral de primeira instância ${ }^{16}$ tem autonomia total para decidir sobre as consultas e arbitrar sobre os processos da sua área de jurisdição (naturalmente com base na legislação, que é a mesma para todo o território nacional). Apenas nos casos de conflito, ou seja, de discordância da decisão do Juiz local, autoridade máxima na eleição municipal, é que a parte que se sente prejudicada recorre ao Tribunal Regional Eleitoral (TRE), podendo levar seu recurso até a última instância, o Supremo Tribunal Federal (STF). Caso contrário, o Tribunal Regional não chega a tomar conhecimento do julgamento ocorrido em nível municipal.

Nesse sentido, a mecânica de funcionamento da Justiça Eleitoral, que garante independência e autonomia aos juízes eleitorais de primeira instância, possibilita a existência de interpretações diferentes, muitas vezes contraditórias, de um mesmo artigo, em municípios de um mesmo estado da Federação. Está configurada a "legalidade da diferença de condições". Essa situação não só é possível como bastante freqüente, motivando duras críticas às atribuições da Justiça Eleitoral ${ }^{17}$.

16 No caso de a Comarca ter mais de uma Zona Eleitoral, cada zona terá um Juiz responsável e os julgamentos e decisões de matérias concernentes às eleições locais serão de responsabilidade do Juiz da Zona Eleitoral de menor número de registro.

17 Segundo Sadek (1995), a estrutura de funcionamento da Justiça Eleitoral não pode ser considerada como o único fator responsável pela pluralidade de interpretações. Aspectos relativos ao Poder Judiciário e à instabilidade eleitoral também contribuem para a heterogeneidade das decisões e também devem ser levados em consideração. Também merecem atenção as evidências de abuso do exercício do papel fiscalizador da Justiça Eleitoral (JARDIM, 2002)

\section{CONTEXTO TÉCNICO DAS TELECOMU- NICAÇÕES}

No Brasil, a radiodifusão de sons e imagens é uma atividade de concessão pública ${ }^{18}$ regulada por um conjunto de leis e de exploração privada. Segundo o Decreto Federal n. 3965 de 10.out.2001, é de responsabilidade do Ministério das Comunicações conceder as outorgas, normatizar e fiscalizar o conteúdo da programação. É por meio do Plano Básico de Radiodifusão que podemos verificar as emissoras de televisão legalmente instaladas e os canais ainda disponíveis para utilização. Compete à Agência Nacional de Telecomunicações (ANATEL), entre outras responsabilidades, as questões de regulamentação e fiscalização técnica da utilização do espectro radioelétrico.

Existem quatro modalidades principais de emissoras de televisão em operação no território nacional: as geradoras comerciais, as educativas, as retransmissoras e as retransmissoras educativas mistas. Também existem as emissoras "piratas", que atuam na ilegalidade; elas não foram incluídas no estudo porque - até onde esta pesquisa sondou - em nenhuma delas ocorreu veiculação de propaganda eleitoral ${ }^{19}$. As definições apresentadas e os dados sobre os números das emissoras no estado de São Paulo foram extraídos dos sítios da ANATEL e do Ministério das Comunicações, dos arquivos do jornal Folha de S. Paulo e da Fundação Padre Anchieta:

- "Geradora de Televisão": emissora capaz de gerar e transmitir sons e imagens, destinados ao recebimento direto e livre pelo público em geral. Modalidade presente em dezessete municípios paulistas $^{20}$ mais a cidade de São Paulo.

18 De acordo com a Lei n. 9472/97, a concessão de serviço de telecomunicação consiste na delegação de tal prestação, mediante contrato, por prazo determinado, no regime público, sujeitando-se a concessionária aos riscos empresariais, remunerando-se pela cobrança de tarifas dos usuários ou por outras receitas alternativas e respondendo diretamente pelas obrigações e pelos prejuízos que causar (BRASIL, 1997a).

19 Os políticos têm sido os principais fiscais de irregularidades praticadas pelos meios de comunicação no período de campanha eleitoral porque, na maioria das vezes, sentem-se prejudicados em seus interesses pessoais.

${ }^{20}$ Campinas, Santos, Ribeirão Preto, São José dos Campos, Sorocaba, São José do Rio Preto, Mogi das Cruzes, Bauru, Franca, Limeira, Taubaté, Presidente Prudente, Americana, São Carlos, Araraquara, Araçatuba e Jaú. 
- "Retransmissora de Televisão": é a estação capaz de captar sinais de sons e imagens e retransmiti-los, simultaneamente, para recepção pelo público em geral.

- "Televisão Educativa": é a estação que realiza transmissão sem fins comerciais, sendo vedada inserção de publicidade.

- "Retransmissora Educativa Mista": retransmissoras das redes educativas nacionais - TV Cultura, vinculada à Fundação Padre Anchieta, e TV Educativa-Rede Brasil, vinculada à Fundação Roquette Pinto - com autorização especial para inserção de programação de interesse comunitário (programação local) em até $15 \%$ da programação normal daquelas Emissoras Educativas. Modalidade presente em quarenta e oito municípios paulistas, dos quais apenas seis também são sede de geradoras.

- "Plano Básico de Radiodifusão": é a relação de canais aprovados pela ANATEL para todo o país; para que o canal seja incluído no Plano Básico são necessárias a sua publicação no Diário Oficial da União e aprovação por meio de consulta pública.

Chama a atenção o número bastante reduzido de municípios-sede de geradoras no estado de São Paulo - dezessete mais a capital -, pertencentes às diferentes emissoras comerciais; no entanto, a somatória das suas redes de retransmissoras resulta em uma cobertura de sinal de sons e imagens de $100 \%$ dos municípios paulistas ${ }^{21}$.

Das modalidades de emissoras de televisão existentes, as relacionadas ao acesso dos municípios ao HGPE em eleições locais são as geradoras comerciais e as retransmissoras educativas mistas, pois são as únicas em plenas condições técnicas para a geração de imagem própria. Em outras palavras, todas as geradoras comerciais estão obrigadas a transmitir o HGPE para todos os pleitos sejam proporcionais, sejam majoritários Presidente, Governador e Prefeito, senadores, deputados federais, deputados estaduais e vereadores. Da mesma forma, as retransmissoras

21 Eventualmente um ou outro município, principalmente nas regiões de divisa do estado, pode receber o sinal de geradoras sediadas em municípios pertencentes a outros estados. educativas mistas, pois são elas as responsáveis pela transmissão de programação local ${ }^{22}$, veiculando informações e aspectos da cultura e política do Município onde estão sediadas e que não têm espaço nas grandes redes comerciais de caráter estadual e nacional.

As retransmissoras educativas mistas apresentam características tão específicas que confundem até mesmo os profissionais da área de comunicações. Foram criadas oficialmente em 1991, por meio da Portaria Interministerial n. 236, de 29.out.1991, dos Ministérios das Comunicações e da Educação. Essa modalidade de televisão, que passarei a denominar de "emissora local", nada mais é do que uma retransmissora de Televisão Educativa - TV Cultura-SP ou TV Educativa-Rede Brasil-RJ - com autorização para inserção de programação de interesse comunitário em até $15 \%$ da programação da emissora cabeça-de-chave. É importante dizer que as retransmissoras mistas existem em todo o território nacional. As "emissoras locais" não devem ser confundidas com "televisão comunitária" 23 nem com os canais disponíveis nas televisões por assinatura ${ }^{24}$.

Quando se analisa o conjunto de regulamentações sobre as Retransmissoras Educativas Mistas, mais uma vez - como nos casuísmos sofridos

22 As retransmissoras educativas mistas, quando autorizadas pelo Juiz Eleitoral local, também estão tecnicamente habilitadas para a transmissão da propaganda eleitoral gratuita nas campanhas para prefeitos.

23 Ao contrário do que ocorre com a modalidade rádio, a figura da "televisão comunitária" não existe legalmente. O custo envolvido na montagem e manutenção de uma emissora ou retransmissora de televisão é relativamente elevado - o que, por si só, inibe iniciativas de pirataria.

24 Coincidentemente, a televisão paga no Brasil inicialmente via cabo e depois via satélite - também teve início em 1991. A televisão paga trouxe novas tecnologias de difusão de sons e imagens e opções de programação; possibilitou, inclusive, a segmentação da audiência. A legislação que regulamentou este serviço de telecomunicação permitiu a participação de capital estrangeiro e exigiu, em troca da autorização de funcionamento, a apresentação de canais para fins de utilidade pública, ligados ao poder público e às universidades. Assim nasceram a TV Senado, a TV Câmara e uma infinidade de televisões vinculadas às assembléias legislativas e câmaras municipais. São os canais comunitários da cabodifusão que têm sido exemplo de prática democrática - já que, muitas vezes, são partilhados por várias entidades - e na variedade das informações veiculadas. 
pela legislação eleitoral - observa-se que os interesses políticos têm desempenhado importante papel nas mudanças ocorridas na legislação. No entanto, é importante ressaltar que os interesses da classe política não são os únicos fatores a determinar mudanças, muitas vezes radicais nas regras de funcionamento dessas emissoras. A forma de atuar das "emissoras locais", nem sempre atentas ao cumprimento da legislação em vigor, apesar de bastante heterogêneas quando comparadas entre si, também vem influenciando as decisões do poder Executivo ${ }^{25}$.

\section{ALEGISLAÇÃO ELEITORALE O HGPE NA TV: IMPRECISÕES E HETEROGENEI- $\mathrm{DADE}^{26}$}

No Brasil, a história da propaganda política na televisão confunde-se com a história da própria televisão. Desde o início da sua operação, os políticos souberam explorar esse poderoso meio de comunicação. A relação da propaganda eleitoral com a legislação eleitoral teve início com a Lei n. 4 115, de 22.ago.1962, quando o Deputado Federal por Pernambuco, Adauto Lúcio Cardoso, teve aprovado seu Projeto de Lei que instituía o horário gratuito de propaganda eleitoral - o "Guia Eleitoral". Conhecida como Lei Adauto Cardoso, em seu Artigo 11, parágrafo $3^{\circ}$, previa a gratuidade da propaganda eleitoral nas "estações de radiodifusão e televisão de qualquer potência". A televisão era coisa recente no país e sua abrangência e cobertura bastante limitadas, além de as emissoras serem em número bem reduzido. A importância da televisão, na vida cultural e política do país, ainda estava por ser construída.

Em 1974, com a Lei n. 6091 de 15.ago.1974, chegou ao fim a propaganda política paga na televisão que, desde 1962 com a Lei Adauto, convivia com a propaganda gratuita. A partir de então, observou-se que na redação dos artigos referentes à propaganda eleitoral na televisão existe

25 Para uma discussão sobre as retransmissoras educativas mistas, ver texto do jornalista Gabriel Priolli (2002).

26 Este artigo limita-se apenas aos aspectos que dizem respeito à obrigatoriedade e gratuidade da transmissão da propaganda eleitoral na televisão. Em mais de quarenta anos do HGPE, foram dezenas de leis e resoluções sobre a matéria que não apresentam um significado maior quando mencionadas isoladamente. Nesse sentido, é importante analisá-las em seu conjunto e no contexto político em que foram elaboradas. uma preocupação em deixar clara a obrigatoriedade da transmissão gratuita (lembrando que a obrigatoriedade de transmissão da propaganda eleitoral no rádio e na televisão é prevista para todos os pleitos, majoritários e proporcionais). Até a eleição municipal de 1988 a aplicação desse aspecto da legislação eleitoral transcorreu dentro da maior tranqüilidade, sem nenhuma divergência quanto à transmissão da propaganda eleitoral na televisão. Em 1989, na primeira eleição direta para Presidente da República depois de 29 anos, a única novidade foi a exigência de formação de rede nacional. Não houve dificuldade, em todo o território nacional, para o cumprimento dessa norma, já que as emissoras comerciais dispunham de acesso a satélites desde a década de 1970. A eleição para governadores em 1990 não apresentou novidades - inclusive porque foi regulamentada apenas pelo TSE, na medida em que os parlamentares do Congresso Nacional perderam o prazo para aprovação de lei eleitoral27.

Por outro lado, os pleitos municipais que se seguiram a 1990 tiveram nova dimensão, que foi dada pela Portaria Interministerial n. 236, de 29.out.1991, que criou a figura das Retransmissoras Educativas Mistas. Até então, apenas os municípios-sede das geradoras transmitiam o HGPE na televisão. A partir das eleições municipais de 1992, passaram a existir as "emissoras locais" e, com elas, a possibilidade de "palanque eletrônico" para as eleições locais de municípios que não eram sede de geradoras comerciais. Assim, tiveram início as divergências de interpretação da legislação eleitoral, que persistem até o momento 28 .

A lei que disciplinou a eleição municipal de 1992 (Lei n. 8 214, de 24.jul.1991) foi elaborada e aprovada em julho de 1991, ou seja, foi anterior à criação das "emissoras locais", o que poderia justificar a ausência de sua menção. A Lei n. 8 713, de 30.set.1993, que estabeleceu as normas para as eleições gerais de 1994, apresentou várias

27 De acordo com o Artigo 16 da Constituição Federal de 1988, a legislação eleitoral precisa ser aprovada com uma antecedência mínima de 12 meses da realização do pleito.

28 Até a conclusão deste texto, prevalecia em vigor a Lei n. 9 504, de 30.set.1997, que tem no teor do seu Artigo 57 o conteúdo das interpretações divergentes sobre as emissoras de televisão, que estariam obrigadas a transmitir o HGPE. 
novidades com relação à propaganda eleitoral na televisão ${ }^{29}$. Mas, como já mencionado, nosso interesse está centrado na transmissão do HGPE na televisão para eleições locais, ou seja, o "palanque eletrônico" para eleição dos prefeitos no estado. Nesse sentido, merece destaque o Artigo 58 da Lei n. 9 100/95: "Não havendo emissora de televisão no Município, os órgãos regionais de direção da maioria dos partidos participantes do pleito poderão requerer à Justiça Eleitoral que reserve, dentre as geradoras de imagens que alcancem, aquela que deixará de formar rede para transmitir o programa gratuito dos candidatos do Município.

$\S 1^{\circ}$ - A Justiça Eleitoral, recebendo o pedido, designará a emissora de maior audiência, dentre as geradoras, para transmitir o programa dos candidatos do Município-sede, e as demais, na ordem do eleitorado de cada município por elas alcançado, até o limite das disponíveis.

$\S 2^{\circ}$ - Nesse caso, na abertura do programa eleitoral, cada uma das emissoras informará quais os municípios cujos programas serão transmitidos e quais as emissoras que os transmitirão.

$\S 3^{\circ}-\mathrm{O}$ órgão de direção municipal de partido de município contemplado com a geração do programa de seus candidatos poderá ceder parte do tempo de que dispuser a candidatos do mesmo partido, de outros municípios [...]" (BRASIL, 1995).

É fácil perceber, apenas pela leitura do artigo, que ele é de difícil execução. São muitos os interesses e as variáveis envolvidos. A legislação no Brasil é feita pelos senadores e deputados federais, muitas vezes após discussão e aprovação nas Comissões e, também, após sugestões de especialistas e assessores técnicos. Apesar desses procedimentos, não é incomum a aprovação de leis inviáveis ou de difícil execução prática. Também não se pode perder de vista que os parlamentares são, em sua maioria, eternos candidatos e acabam legislando em causa própria.

O Artigo 58 da Lei n. 9 100/95 parecia, em princípio, um mecanismo bastante interessante e justo para solucionar o problema dos municípios com grandes contingentes de eleitores e importância política, mas que não contavam com

29 Para detalhes, cf. Jardim (2002). "palanque eletrônico" para suas eleições locais. No entanto, esse artigo teve sua viabilidade questionada pela Associação Brasileira de Rádio e Televisão $(\mathrm{ABERT})^{30}$, que chamava a atenção para as dificuldades técnicas de implementação da segmentação geográfica do HGPE na televisão, como ficou conhecido esse artigo. Essa primeira barreira foi ainda mais agravada pelas imensas e intransponíveis barreiras políticas locais. A lei previa que as direções da maioria dos partidos participantes do pleito do município interessado fizessem a requisição do tempo. A observação da realidade tem indicado que, se não é impossível, a formação de consenso entre as direções de partidos políticos concorrentes é bastante difícil. Uma segunda dificuldade, também de ordem política, residia na pressão que, muito provavelmente, seria exercida pela direção regional dos partidos sobre as executivas municipais ao verem a "pupila dos olhos" das campanhas eleitorais - o "palanque eletrônico" - segmentar-se entre os municípios pelas emissoras de televisão. Não há como negar que a confusão inicial causada pela não-formação de rede de transmissão poderia causar queda nos índices de audiência. Tampouco é factível com a realidade política o $\S 3^{\circ}$, que previa a cessão de parte do tempo dos diretórios municipais para candidato do mesmo partido de município desprovido de geradora comercial. Qual o candidato que concordaria com a perda de minutos tão preciosos para sua campanha? Previsivelmente, esse artigo caiu com a lei subseqüente, a Lei n. 9 504, de 30.set.1997. Não encontramos, nem nos registros do TRE-SP nem nos arquivos do jornal Folha de S. Paulo, referências ao uso de tempo na televisão proveniente da segmentação geográfica.

A Lei n. 9 504/97 interessa-nos em particular porque disciplinou o pleito municipal de $2000 \mathrm{e}$ disciplinará o de 2004. Em substituição à inviável segmentação geográfica, o Artigo 48 prevê : "Nas eleições para Prefeitos e Vereadores, nos Muni-

\footnotetext{
30 Apesar de ser um serviço de concessão pública, as emissoras de rádio e televisão são reembolsadas pelo governo federal, por meio de ressarcimento fiscal pelo tempo cedido para transmissão do HGPE. As emissoras, de maneira organizada, passam não só a acompanhar o processo de reformulação da legislação, mas também buscam mecanismos de influência e pressão para verem seus interesses garantidos.
} 
cípios em que não haja emissora de televisão, os órgãos regionais de direção da maioria dos partidos participantes do pleito poderão requerer à Justiça Eleitoral que reserve dez por cento do tempo destinado à propaganda eleitoral gratuita para divulgação em rede da propaganda dos candidatos desses Municípios, pelas emissoras geradoras que os atingem.

$\S 1^{\circ}$ - A Justiça Eleitoral regulamentará o disposto neste artigo, dividindo o tempo entre os candidatos dos Municípios vizinhos, de forma que o número máximo de Municípios a serem atendidos seja igual ao de emissoras geradoras disponíveis [...]" (BRASIL, 1997b).

Novamente, dificuldades à vista. Mais uma vez se requer consenso da maioria da direção dos partidos envolvidos no pleito e, desta vez, a lei especifica suas direções regionais. As emissoras não poderão alegar dificuldades técnicas nem os candidatos poderão alegar confusão porque a transmissão continuará feita em rede. A novidade é que se poderá requerer $10 \%$ do tempo do horário longo destinado à propaganda eleitoral gratuita para distribuição entre os candidatos dos municípios atingidos pelas geradoras. Sem grandes contas matemáticas, pode-se prever que três minutos na hora do almoço e mais três minutos no horário nobre - para serem divididos entre todos os candidatos dos municípios atingidos pelas geradoras - afinal não despertam tanto interesse assim. É verdade que o Artigo 48 da Lei n. 9 504/97 não é muito divulgado, mas, mesmo que fosse, a produção da propaganda, mais a negociação entre os partidos e candidatos dos municípios envolvidos, mais os requerimentos legais junto à Justiça Eleitoral tendem a desequilibrar a relação dos custos e benefícios envolvidos nessa "odisséia televisiva".

Mas é o Artigo 57 da Lei n. 9 504/97 que mais diretamente importa, pois é com base em sua interpretação que os juízes eleitorais de primeira instância justificam os pareceres dando permissão ou proibição de as "emissoras locais" veicularem o HGPE em eleições locais: "As disposições desta Lei aplicam-se às emissoras de televisão que operam em VHF e UHF e os canais de televisão por assinatura sob a responsabilidade do Senado Federal, da Câmara dos Deputados, das Assembléias Legislativas, da Câmara Legislativa do Distrito Federal ou das Câmaras Municipais" (ibidem).
Em geral, como em muitas outras decisões do poder Judiciário, nem sempre os critérios que norteiam as decisões são transparentes. Como já mencionado, os juízes eleitorais dos municípios (juízes de primeira instância) têm autonomia e o Tribunal Regional Eleitoral só toma conhecimento das matérias julgadas no nível dos municípios em grau de recurso por parte interessada. Essa lógica faz que existam municípios autorizados pelo Juiz Eleitoral local a transmitir o HGPE na televisão para Prefeito e municípios que estão proibidos. Outros municípios já transmitiram no passado e foram proibidos na eleição de 2000, como é o caso de Mococa. Existem, ainda, aqueles que transmitem o HGPE em situação relativamente irregular, ou seja, sem nenhuma determinação oficial por parte da Justiça Eleitoral, que só poderá manifestarse caso algum partido participante da eleição sintase prejudicado e entre com representação judicial. Por fim, há os municípios que possuem "emissoras locais" mas cujos políticos, líderes partidários e os responsáveis pelos meios de comunicação locais não têm conhecimento - pelo menos não divulgado publicamente - da possibilidade de veiculação do HGPE, em contraste com outras localidades que o fazem.

Na verdade, o que se verifica é que não existe uma regra. O Artigo 57 da Lei n. 9 504/97 prevê a obrigatoriedade da transmissão do HGPE apenas para emissoras que operem em VHF e UHF e para os canais por assinatura sob responsabilidade dos poderes públicos. É exatamente a designação de "emissoras" que dá margem a diferentes interpretações. Alguns juízes do estado de São Paulo interpretam "emissoras" como referindo-se - única e exclusivamente - aos dezoito municípios-sede de geradoras comerciais existentes no estado. Sendo assim, proíbem, sob pena de punição prevista na legislação em vigor, a veiculação do HGPE para Prefeito nos municípios-sede das Retransmissoras Educativas Mistas. Por outro lado, outros juízes interpretam "emissoras" como referindo-se a qualquer tipo de emissora de televisão, seja Geradora Comercial, seja Retransmissora Educativa Mista, permitindo a transmissão do HGPE para as eleições locais.

Como reflexo dessa lógica de funcionamento da Justiça Eleitoral e da autonomia dos juízes eleitorais, encontramos uma grande diversidade de situações nos municípios-sede de "emissoras locais" com relação à veiculação do HGPE na 
televisão em eleições locais. No Município de Sertãozinho, por exemplo, o Juiz Eleitoral acatou solicitação dos partidos locais para que não houvesse o HGPE na televisão na eleição de 2000. Já em Mococa, que veiculava a propaganda eleitoral gratuita há duas eleições, o Juiz Eleitoral determinou - após julgar pedido encaminhado por um dos partidos que se sentiu prejudicado - a proibição do "palanque eletrônico" nas eleições de 2000. Um dos argumentos recorrentes utilizados tanto por políticos como por juízes é o de que a propaganda eleitoral na televisão em centros urbanos de pequeno e médio porte ${ }^{31}$ encareceria as campanhas. No entanto, não há nenhuma comprovação de que o HGPE na televisão torne as campanhas eleitorais mais caras, possibilitando que candidatos possam alegar desigualdade de condições ou abuso de poder econômico. Pelo contrário, em municípios de porte médio poderse-ia dizer justamente o oposto, que o HGPE na televisão contribui para o barateamento da campanha, pois, contando com o apoio da propaganda televisiva, poderia produzir material gráfico em menor quantidade e substituir os "showmícios" pelo "palanque eletrônico". Assim, a análise das decisões dos juízes eleitorais nos municípios-sede de "emissoras locais" pode entendê-las como práticas arbitrárias e mesmo autoritárias ${ }^{32}$, em que os interesses políticos das forças locais têm prevalecido sobre o direito do eleitor de ter acesso à informação política.

\section{PALANQUEELETRÔNICO NAS ELEIÇÕES DE 2000}

Em resumo, do ponto de vista do principal meio de comunicação de massa da sociedade contemporânea - a televisão -, existem duas categorias de campanha eleitoral para eleições locais no estado de São Paulo, a tradicional e a eletrônica. A campanha tradicional utiliza como recursos de comunicação a distribuição de material

31 Este estudo definiu como sendo município de pequeno porte aqueles com até 30000 eleitores e de porte médio, os municípios com eleitorado entre 30000 e 80000 eleitores.

32 Alguns juízes sedimentam sua justificativa no inciso III, $\S 1^{\circ}$, do Artigo $1^{\circ}$ da Lei Falcão que previa que "a propaganda dos candidatos às eleições em um município só poderá ser feita pelas emissoras de rádio e televisão, cuja outorga tenha sido concedida para esse mesmo município, vedada a retransmissão em rede" (Lei n. 6339/76, de 1.jul.1976, revogada em 1985 com a Lei n. 7 332/85). gráfico, ações de contato direto com o candidato majoritário (reuniões, passeatas, carreatas e comícios) e, quando o município é sede de estação de rádio, propaganda gratuita no rádio. A "campanha eletrônica" faz uso dos mesmos recursos da campanha tradicional, mas tem acesso a um significativo recurso adicional, a mídia eletrônica televisiva.

A pesquisa "Aldeia global paulista" mostrou que esse contexto do acesso ao palanque eletrônico em eleições locais é marcado por uma complexa articulação de aspectos legais e técnicos. São dois os aspectos legais envolvidos: o primeiro trata da legislação eleitoral e o segundo, das atribuições e lógica de funcionamento da Justiça Eleitoral. A análise da legislação no período de 1958 a 2000 indica que tem sido reservado apenas um artigo em todo esse período para disciplinar o uso da mídia eletrônica na transmissão da propaganda eleitoral gratuita e que a referência à obrigatoriedade de transmissão tem sido feita apenas às "emissoras". O segundo aspecto legal envolve a atribuição da Justiça Eleitoral de interpretar a legislação eleitoral em vigor, produzindo determinações. Em eleições municipais o Juiz Eleitoral local tem poder decisório de primeira instância e, tradicionalmente, essa referência às "emissoras" tem sido interpretada como significando "geradoras" de televisão.

Todavia, são várias as modalidades de emissoras de televisão em operação no estado de São Paulo, o que nos remete aos aspectos técnicos envolvidos na transmissão da propaganda eleitoral na televisão em eleições locais. A coexistência de diferentes modalidades de transmissão de sons e imagens deve-se, em grande medida, ao modelo adotado pelo regime militar para a expansão do sistema de telecomunicações do Brasil e à criação da modalidade das retransmissoras educativas mistas em 1991.

Do ponto de vista exclusivamente técnico, apenas as modalidades "geradora" e "retransmissora educativa mista" estão habilitadas a transmitir a propaganda eleitoral para eleição local, pois são as únicas que dispõem de recursos para a geração de imagem própria. Apesar de a abrangência da cobertura das redes de televisão atingir a totalidade dos municípios paulistas, a modalidade "geradora" está presente em apenas dezoito, os demais recebendo sinais por meio das retransmissoras e repetidoras. Os quarenta e dois 
municípios-sede, exclusivamente, de retransmissoras educativas mistas, apesar de habilitados para a transmissão, ficam na dependência de decisão do Juiz Eleitoral local para veicular o HGPE.

Dessa forma, juízes eleitorais de diferentes municípios, com base na mesma legislação, julgando a mesma matéria (a transmissão de propaganda eleitoral em emissoras de mesma modalidade), em eleições para o mesmo cargo (Prefeito) no mesmo ano, produzem pareceres absolutamente opostos. Um Juiz pode adotar uma regra em uma eleição e - ele mesmo ou um outro Juiz - adotar regra oposta na eleição seguinte. Como o Tribunal Regional Eleitoral, apesar de conhecer o problema, não disciplinou a questão, configura-se uma instabilidade que compromete a confiabilidade nos procedimentos eleitorais.

A pesquisa "Aldeia global paulista" mostrou que $47 \%$ do eleitorado teve acesso ao horário gratuito na televisão como fonte de informação política nas eleições municipais de 2000, no estado de São Paulo. Mesmo se excetuando a capital - que representa 29\% do eleitorado -, ainda ficamos com um universo bastante significativo representado por $18 \%$ do eleitorado, distribuído em 28 municípios espalhados pelo estado ${ }^{33}$. A grande ausência entre os municípios com palanque ele-trônico para eleições locais é a região da Grande São Paulo, cujos municípios recebem o sinal da propaganda dos candidatos da capital.

Recentes alterações nas regulamentações do Ministério das Comunicações, obrigando as retransmissoras educativas mistas a migrarem para o Plano de Geradoras, transformando-se em geradores, produzirão um aumento considerável no potencial de municípios com "palanque eletrônico". Por outro lado, permanecem as questões de captação de recursos e estrutura técnica e de pessoal para a produção da programação local. Neste momento, não há base para fazer-se uma estimativa de quantas das quarenta e oito "emissoras locais" terão condições técnicas, administrativas e financeiras para passar para o Plano de Geradoras. Essa alteração ocorrerá, muito possivelmente, já nas próximas eleições municipais de 2004.

33 Para tabelas com nome dos municípios e respectivos eleitorados, cf. Jardim (2002).

Márcia Jardim (marciaj@ unicamp.br) é Mestra em Ciência Política pela Universidade Estadual de Campinas (UNICAMP).

\section{REFERÊNCIAS BIBLIOGRÁFICAS}

ALBUQUERQUE，A. 1994. A campanha presidencial no Jornal Nacional : observações preliminares. Comunicação \& Política, Rio de Janeiro, v. 1, n. 1, p. 23-40, ago.-nov.

1995. Política versus televisão : o horá-rio gratuito na campanha presidencial de 1994. Comunicação \& Política, Rio de Janeiro, v. 1, n. 3, p. 49-54, abr.-jul.

AVELAR, L. 1992. As eleições na Era da Televisão. Revista de Administração de Empresas, Rio de Janeiro, v. 32, n. 4, p. 42-57, set.-out.

AZEVEDO, F. 2001. Introdução : A mídia, a democracia de público e a modernização das campanhas eleitorais no Brasil. Teoria \& Pesquisa, São Carlos, n. 36-37, p. 3-13, jan.-jun.

BAYMA, I. F. C. 2000. Dados sobre a concentração da propriedade de meios de comunicação e o coronelismo eletrônico no
Brasil. Brasília : Liderança do Partido dos Trabalhadores na Câmara dos Deputados.

BISPO SOB., J. 1996. Eleições municipais de 1996 : em face da legislação vigente : roteiro. São Paulo : Sugestões Literárias.

CAIAFA, J. 1994. Mídia e poderes : algumas notas e breve esboço de estratégias. Comunicação \& Política, Rio de Janeiro, v. 1, n. 1, p. $73-$ 88, ago.-nov.

CARVALHO, E. 2000. Um balanço da Justiça Eleitoral : da Constituição de 88 à reeleição de 98. Recife. Dissertação (Mestrado em Ciência Política). Universidade Federal de Pernambuco.

COSTA, S. \& BRENER, J. 1997. Coronelismo eletrônico : o governo Fernando Henrique e o novo capítulo de uma velha história. Comunicação e Política, Rio de Janeiro, v. 4, n. 2, p. 29-53, maio-ago. 
CUNHA, S. S. 1994. Avanços e recuos da legislação eleitoral. Comunicação \& Política, Rio de Janeiro, v. 1, n. 1, p. 63-66, ago.-nov.

DIAS, H. S. 1995. Mídia e política : a cobertura de $O$ Globo e a eleição municipal do Rio em 1992. Rio de Janeiro. Dissertação (Mestrado em Ciência Política). Instituto Universitário de Pesquisas do Rio de Janeiro.

GUIMARÃES, C. \& VIEIRA, R. A. A. 1986. A televisão brasileira na transição. Um caso de conversão rápida à nova ordem. Comunicação \& Política, Rio de Janeiro, v. 3, n. 6, p. 1130, jan.-abr.

1989. Meios de comunicação de massa e eleições : um experimento brasileiro. Comunicação \& Política, Rio de Janeiro, v. 1, n. 9, p. 147-157, jan.-abr.

HOLBROOK, T. 1996. Do Campaigns Matter? London : Sage.

JARDIM, M. 2002. O mapa da mídia eletrônica em eleições locais no estado de São Paulo. Campinas. Dissertação (Mestrado em Ciência Política). Universidade Estadual de Campinas.

JOBIM, N. \& PORTO, W. C. (orgs.). 1996. Legislação eleitoral no Brasil : do século XVI a nossos dias. V. 3. Brasília : Senado Federal.

JORGE, V. L. 1995. A eleição presidencial de 1994 e os meios de comunicação de massa. Uma análise da propaganda eleitoral gratuita de Fernando Henrique Cardoso e Luiz Inácio Lula da Silva na televisão. Rio de Janeiro. Dissertação (Mestrado em Ciência Política). Instituto Universitário de Pesquisas do Rio de Janeiro.

1997. Os meios de comunicação de massa nas campanhas eleitorais. Comunicação \& Política, Rio de Janeiro, v. 4, n. 1, p. 126133, jan.-abr.

LEAL, V. N. 1975. Coronelismo, enxada e voto. $5^{a}$ ed. São Paulo : Alfa-ômega.

LIMA, V. A. 1989. The State, Television, and Political Power in Brazil. Comunicação \& Política, Rio de Janeiro, v. 1, n. 9, p. 159183, jan.-abr.

1996. A pesquisa sobre a mídia eletrônica : velhas e novas questões. Comunicação \& Política, Rio de Janeiro, v. 3, n. 2, p. 198204, maio-ago.
MANIN, B. 1995. As metamorfoses do governo representativo. Revista Brasileira de Ciências Sociais, São Paulo, ano 10, n. 29, p. 5-34, out.

MATOS, H. (org.). 1994. Mídia, eleições e democracia. São Paulo : Scritta.

MIGUEL, L. F. 1997. Mídia e discurso político nas eleições presidenciais de 1994. Comunicação \& Política, Rio de Janeiro, v. 4, n. 1, p. 80-96, jan.-abr.

1999. A campanha de 1998 na Rede Globo. Dados, Rio de Janeiro, v. 42, n. 2, p. 253-276.

MOTTER, P. 1994. O uso político das concessões das emissoras de rádio e televisão no governo Sarney. Comunicação \& Política, Rio de Janeiro, v. 1, n. 1, p. 89-116, ago.-nov.

PORTO, M. P. 1996. Televisão e voto : a eleição de 1992 para Prefeito de São Paulo. Opinião Pública, Campinas, v. IV, n. 1, p. 41-49, abr.

PRIOLLI, G. 2002. Um olhar sobre a cultura brasileira : rádio e televisão. Brasília : Ministério da Cultura. http://www.minc.gov.br. Acesso em : mar.2002.

RONDELLI, E. \& WEBER, M. H. 1994. Ensaio das eliminatórias : os media e o campeonato eleitoral. Comunicação \& Política, Rio de Janeiro, v. 1, n. 1, p. 41-52, ago.-nov.

RUBIM, A. A. C. 1994. Política, media e eleições : 1989 e 1994. Comunicação \& Política, Rio de Janeiro, v. 1, n. 1, p. 53-62, ago.-nov.

2002. Das visibilidades das eleições de 2002 : uma reflexão acerca dos enlaces entre política, mídia e cultura. Artigo apresentado no XXVI Encontro Anual da Associação Nacional de Pós-Graduação e Pesquisa em Ciências Sociais, realizado em Caxambu (MG), de 22 a 26.out.2002. Digit.

SADEK, M. T. 1995. A Justiça Eleitoral e a consolidação da democracia no Brasil. V. 4. São Paulo : Fundação Konrad AdenauerStiftung.

1990. A Justiça Eleitoral no processo de redemocratização. In : LAMOUNIER, B. (org.). De Geisel a Collor : o balanço da transição. São Paulo : IDESP.

2000. Justiça Eleitoral. In : BRASIL. Ministério das Relacões Exteriores. Brasil. Brasília : Ministério das Relações Exteriores. CD-Rom. 
SCHMITT, R., PIQUET, L. \& KUSCHNIR, K. 1999. Estratégias de campanha no horário gratuito de propaganda eleitoral em eleições proporcionais. Revista Brasileira de Ciências Sociais, São Paulo, v. 42, n. 2, p. 277-301.

SEADE. 2002. Anuário Estatístico do estado de São Paulo. São Paulo : Fundação Sistema Estadual de Análise de Dados.

SKIDMORE, T. 1993. Television : Politics and the Media in a Democratizing Latin America. In : Television, Politics, and Transition to Democracy in Latin America. Washington, D. C. : Woodrow Wilson Center.

STRAUBHAAR, J., OLSEN, O. \& CAVALLARI, M. N. 1991. The Role of Television in the
1989 Brazilian Presidential Election. Occasional Papers, n. 6. Providence : The Thomas J. Watson Jr. Institute for International StudiesBrown University.

TRE-SP. 2004. Como nasceu o TRE. O Tribunal Regional Eleitoral nasceu no Palácio da Justiça. São Paulo : Tribunal Regional Eleitoral de São Paulo. Disponível em : http://www.tresp.gov.br/institucional/cemel/nasceu.htm. Acesso em : 10.jun.2004.

VIDAL, D. 1998. Categorias morais, mídia e voto numa favela do Recife. Comunicação \& Política, Rio de janeiro, v. 5, n. 2, p. 103-121, maio-ago.

WOLTON, D. 1996. Elogio do grande público. São Paulo : Ática.

\section{OUTRASFONTES}

BRASIL. 1995. Lei n. 9 100, de 29.set. Estabelece normas para a realização das eleições municipais de 3 de outubro de 1996, e dá outras providências. Diário Oficial da União, Brasília, 2.out.1995. Disponível em : http:// www.planalto.gov.br/ccivil_03/Leis/ L9100.htm. Acesso em : 10.jun.2004.

1997a. Lei n. 9472, de 16.jul. Dispõe sobre a organização dos serviços de telecomunicações, a criação e funcionamento de um órgão regulador e outros aspectos institucio- nais, nos termos da Emenda Constitucional n. 8, de 1995. Diário Oficial da União, Brasília, 17.jul.1997, p. 15 081. Disponível em : http:// www.planalto.gov.br/ccivil_03/Leis/ L9472.htm. Acesso em : 10.jun.2004.

1997b. Lei n. 9 504, de 30.set. Estabelece normas para as eleições. Diário Oficial da União, Brasília, 1.out.1997, p. 21801. Disponível em : http://www.planalto.gov.br/ ccivil_03/Leis/L9504.htm. Acesso em : 10.jun.2004. 